\title{
Duration of Diestrous Period and Secretion of Progestins during Prolonged Lactation in the Rat
}

\author{
Hiroshi TOMOgAne, Katuaki ÓtA and Akira YOKOYAMA \\ Faculty of Agriculture, Nagoya University, \\ Chikusa-ku, Nagoya 464
}

\begin{abstract}
Synopsis
The duration of the diestrous period in vaginal smears and the levels of progestins in ovarian venous blood were investigated in rats whose lactation period was prolonged by replacing pups at appropriate intervals.

In prolonged lactating rats, the first diestrous period after the postpartum ovulation $(21.7 \pm 0.8$ days) was similar to that occurring in normal lactating rats. Subsequently proestrous or estrous vaginal smears reappeared at intervals during prolonged lactation. A total of 19 rats were studied during this period of prolonged lactation and 44 diestrous periods were observed. Forty-eight \% of these periods ranged in length from 11 to 16 days (mean of 12.7). Very short diestrous periods lasting less than 3 days were observed $25 \%$ of the time. Diestrous periods lasting more than 17 days were observed only infrequently (7\%).

Progesterone concentration in the ovarian vein during the 2 nd diestrous period reached a peak 4 days after the 1 st estrus and the level was maintained until 11 days after the 1 st estrus. The level of $20 \alpha$-hydroxypregn-4-en-3-one remained fairly constant throughout the 2 nd diestrous period.
\end{abstract}

A considerable number of observations have been made on the change in lactational performance in prolonged lactating rats. Lactation was prolonged beyond the normal period by replacing pups at appropriate intervals (Nicoll \& Meites, 1959; Bruce, 1961; Kurz, 1967; Thatcher and Tucker, 1968). However, only a few papers have appeared concerning the ovarian function during a prolonged lactating period (Selye \& McKeown, 1934; Bruce, 1961).

We have been working on the maintenance of luteal function during lactation with special reference to the luteotropic action of prolactin and have reported the pattern of progestin secretion (Tomogane et al., 1969) and the effect of ergocornine,

Received for publication December 8, 1975. a specific inhibitor of the release of prolactin, on progestin secretion (Tomogane et al., 1975) in normal lactating animals. Therefore, it was of interest to study the pattern of progestin secretion in prolonged lactating rats showing fairly long diestrous periods (Selye \& McKeown, 1934; Bruce, 1961).

\section{Materials and Methods}

Primiparous rats of the Wistar-Nagoya strain weighing 200-250 $\mathrm{g}$ and having more than eight pups at parturition were used for the experiment. The day on which the newborn young were first found in the morning was designated day 0 of lactation, and the number of pups per litter was adjusted to eight within 2 days of birth and maintained throughout the experimental period. Animals were kept in a temperature- $\left(24 \pm 2^{\circ} \mathrm{C}\right)$ and light$(05.00 \mathrm{~h}$ to $19.00 \mathrm{~h})$ controlled animal room. Food 
(CLEA-CA-1, Nihon CLEA Ltd., Tokyo) and water were given ad libitum. Vaginal smears were examined and the mother and pups were weighed separately every morning between 09.00 and $09.30 \mathrm{~h}$.

The litters of the lactating rats were replaced by healthy and active new ones of 4-6 days old on day 10 of lactation in the 1 st group, on day 14 and on day 17 or 18 of lactation in the 2 nd and the 3 rd groups, respectively. Thereafter, litters were renewed with 4-6 day old pups at intervals of 5-13 days, mainly of 9 days. By this procedure the lactation period was prolonged to a maximum of 60 days. Lactating rats the pups of which were not replaced served as controls.

In lactating rats, the proestrous and estrous vaginal smears did not necessarily appear in the order seen in non-lactating cyclic rats; proestrous smears not followed by estrous smears as well as estrous smears not preceded by proestrous smears were often observed. Therefore, a diestrous period was considered to be terminated with the appearance of either proestrous or estrous smears, even when diestrous vaginal smears continued again thereafter. We defined the day on which either proestrous or estrous smears (estrogenic smears) appeared at the time corresponding to the end of normal lactation as the first estrogenic day. Since the estrogenic vaginal smears reappeared thereafter at intervals, they were designated in order as the second, the third and the fourth estrogenic day. The period between day 2 of lactation (the day after the postpartum ovulation) and the day before the first estrogenic day was defined as the first diestrous period. Hence, diestrous periods between the first and the 2 nd estrogenic days, and between the 2 nd and the 3rd estrogenic days were called the 2 nd and the 3rd diestrous periods, respectively.

Animals of Groups 1 and 2 were killed by exsanguination under light ether anesthesia on each day on which typical vaginal estrus was shown in prolonged lactation. Ovulation was checked by examination of the oviduct under a microscope for the presence of ova.

Levels of progestins in the ovarian vein blood were measured in rats of Group 3. In all rats of this group, a proestrous smear was always followed by an estrous vaginal smear throughout the experimental period. Therefore, blood samples were collected $1,4,7$, and 11 days after the day of the 1 st estrus (21-28 days of lactation) and on the day of the 2nd estrus. The methods of collection of blood samples from the ovarian vein and of determination of progestins in the sample were similar to those described in the previous paper (Tomogane et al., 1969).

Student's $t$-test was used for the statistical analysis.

\section{Results}

\section{Length of the diestrous period in prolonged lactating rats}

Table 1 illustrates the length of the diestrous period for groups in which the 1 st replacement of pups was performed on different days of lactation. The duration of the 1st diestrous period was very similar in all experimental groups. The overall mean for the length of the 1st diestrous period in the three experimental groups was $21.7 \pm 0.8$ (mean \pm S.E.M.) days. This value was 2 days longer than that in the control group $(19.7 \pm 0.7)$, but the difference was not statistically significant. Three out of 19 rats in the experimental groups showed relatively long diestrous periods $(27,28$ and 29 days), while the mean duration for the remaining rats was $20.6 \pm 0.6$ days.

In 21 out of 44 occasions observed in 19 prolonged lactating rats, the duration of the 2 nd or the 3 rd diestrus was within a range of 11 to 16 days, with a mean of $12.7 \pm 0.3$ day (Table 2 ). Very short diestrous periods of less than 3 days and diestrous periods longer than 17 days were also observed in 11 and 3 occasions, respectively.

Table 1. Relationship between the length of the diestrous period and the date of the $1 \mathrm{st}$ replacement of pups in prolonged lactating rats

\begin{tabular}{ccc}
\hline Group & $\begin{array}{c}\text { Date of the 1st } \\
\text { replacement of pups } \\
\text { (day of lactation) }\end{array}$ & $\begin{array}{c}\text { Length of the 1st } \\
\text { diestrous } \\
\text { period (days) }\end{array}$ \\
\hline 1 & 10 & $22.5 \pm 1.7^{\mathrm{a}}(4) \mathrm{b}$ \\
2 & 14 & $21.6 \pm 1.4(7)$ \\
3 & 17 or 18 & $21.5 \pm 1.3(8)$ \\
\hline $\begin{array}{c}\text { Groups 1-3, } \\
\text { combined }\end{array}$ & $21.7 \pm 0.8(19)$ \\
\hline $4^{\mathrm{c}}$ (control) & & $19.7 \pm 0.6(10)$ \\
\hline
\end{tabular}

a: Mean \pm S.E.M.

b: Number of rats examined.

c: Pups were not replaced.

No significant differences were found among the values of Groups 1-4. 
The longest diestrous period observed during prolonged lactation was 20 days.

Ova were found in the fallopian tubes of all rats killed on the morning of estrus in prolonged lactation.

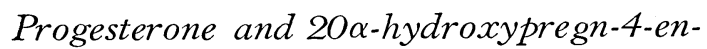
3-one $(20 \alpha-O H P)$ concentration in the ovarian vein blood in various stages of prolonged lactation

Concentrations of progesterone and $20 \alpha$ OHP in the ovarian vein blood in various stages of prolonged lactation are illustrated in Fig. 1. During the 2nd diestrous period of prolonged lactation (Fig. 1), the proge-

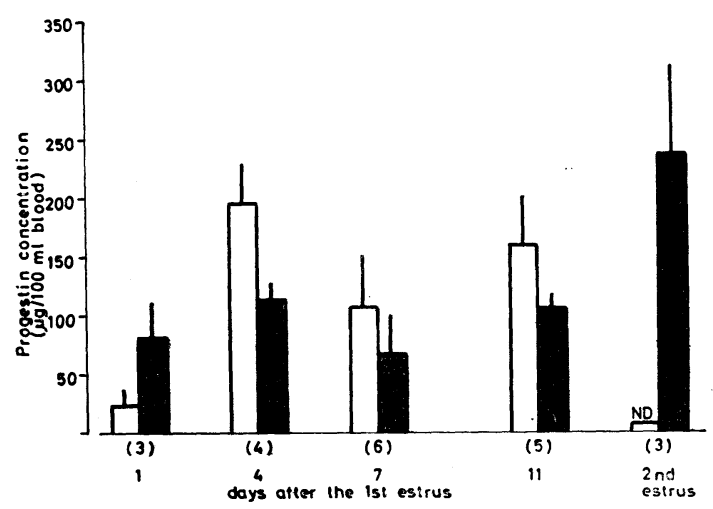

Fig. 1. Progesterone and 20 $\alpha$-hydroxypregn-4-en-3one $(20 \alpha-\mathrm{OHP})$ concentration in ovarian vein blood in various stages of prolonged lactation. Open and solid bars represent mean values for progesterone and 20 $\alpha-\mathrm{OHP}$, respectively. Numbers in the parenthesis indicate number of animals used. The vertical lines indicate+S.E.M.

ND: not detectable. sterone concentration in the ovarian vein blood increased rapidly and reached a peak 4 days after the 1 st estrus $(193.7 \pm 33.2$ $\mu \mathrm{g} / 100 \mathrm{~m} l$ blood). Secretion of progesterone was maintained at about this level throughout the period between 4 and 11 days. No progesterone could be detected in the ovarian vein blood on the day of the 2 nd estrus. The concentration of $20 \alpha-\mathrm{OHP}$ one day after the 1 st estrus was $81.2 \pm 29.0 \mu \mathrm{g} / 100$ $\mathrm{m} l$ blood. The level of $20 \alpha-\mathrm{OHP}$ during the 2nd diestrous period remained fairly constant between 60 and $150 \mu \mathrm{g} / 100 \mathrm{ml}$ blood. On the day of 2nd estrus, the concentration increased up to the level $(234.8 \pm 76.9 \mu \mathrm{g} / 100 \mathrm{~m} l$ blood $)$ which was comparable to the concentration on day 21 of normal lactation.

\section{Discussion}

No significant difference was found in the day of appearance of the 1st estrus between the prolonged and normal lactating. animals, i.e. by day 23 of lactation. Although the suckling stimulus is known to suppress. release of gonadotropins (Rothchild, 1960; McCann \& Ramirez, 1964 ; Ford \& Melampy, 1973; Hammons et al., 1973), it is unlikely that the recurrence of estrus at the end of normal lactation is due to a reduction in frequency or intensity of suckling resulting from the growth of pups. In the present experiment, proestrous or estrous smears appeared mostly between day 21 and 24 of

Table 2. Distribution of the length of diestrous period after the 1 st estrogenic day ${ }^{\mathrm{a}}$ in prolonged lactating rats

\begin{tabular}{|c|c|c|c|c|c|}
\hline & \multicolumn{4}{|c|}{ Length of diestrous period (days) } & \multirow{2}{*}{$\begin{array}{c}\text { Total No. of } \\
\text { diestrous period } \\
\text { observed }\end{array}$} \\
\hline & $2-3$ & $4-10$ & $11-16$ & $17-20$ & \\
\hline $\begin{array}{l}\text { No. of diestrous } \\
\text { period observed }\end{array}$ & 11 & 9 & 21 & 3 & 44 \\
\hline $\begin{array}{l}\text { Percentage to total } \\
\text { No. of observation }\end{array}$ & 25.0 & 20.5 & 47.7 & 6.8 & 100 \\
\hline
\end{tabular}

a: The day on which proestrous or estrous vaginal smears were observed.

$\mathrm{b}$ : The data obtained from 19 rats : 12 rats lactating for 50-60 days and 7 rats for 35-44 days. 
lactation despite the difference in the date of replacement of pups. Therefore, the results of the present experiment show clearly that vigorous suckling stimuli failed to prevent the recurrence of estrous smears at the end of normal lactation.

In contrast to the uniform length of the 1st diestrous period, the variations in the 2nd and the 3rd diestrous periods were very large. The duration of the diestrus in 21 out of 44 periods observed was within the range of the normal length of pseudopregnancy, and short diestrous periods, less than 3 days, appeared in 11 out of 44 observations. In 3 cases, the length of diestrous period was comparable to that of the 1st diestrus in the normal lactating period. Bruce (1961) reported that an increase in the length of estrous cycle in the prolonged lactation was roughly related to the strength of the suckling, and stated that strong suckling by young of more than 8-days old was required to obtain a diestrous period comparable to the normal lactating period. In the present experiments, the variation in the diestrous period could not be attributed to the variation in the intensity of the suckling by foster pups, since we placed 8 pups of similar age and weight with mothers throughout the normal and prolonged lactation. The use of the relatively younger pups for fostering (4-6 days old) in the present experiment, corresponding to the weak suckling in the classification of Bruce (1961), might result in the short diestrous period observed in a considerable number of rats of the present experiments. Although the mechanisms by which various lengths of the diestrous period appeared during the course of prolonged lactation are at present not known, the following concept, together with the relative weakness of the suckling stimuli, could explain the variation. The effectiveness of suckling stimuli either to suppress gonadotropin secretion or to promote prolactin secretion might differ between the period of normal and prolonged lactation as well as between individual animals in prolonged lactating stages.

Our recent experiment, involving the administration of ergocornine (Tomogane et al., 1975) or antiserum to rat prolactin (Tomogane et al., 1976), indicated that the secretion of progesterone from the ovary in lactating rats was mainly stimulated by prolactin. Therefore, the fact that the level of progesterone during the 1st diestrous period as reported previously (Tomogane et al., 1969) was higher than that during the 2nd diestrous period might be due to the higher levels of prolactin secreted under the influence of suckling stimulus and exteroceptive stimuli originated from young pups (Grosvenor et al., 1970; Mena \& Grosvenor, 1972) in the former period. The stimulative effect of the suckling on prolactin secretion in rats has been well demonstrated by many workers (Amenomori et al., 1970; Terkel et al., 1972; Ford \& Melampy, 1973; Yanai \& Nagasawa, 1973). Since suckling by young of the same age was provided during either the 1 st or the 2 nd diestrous period, the discrepancy in secreting levels of prolactin and/or progesterone between these stages may be due to the difference in either the sensitivity of prolactin secretory mechanism in the hypothalamus to suckling and exteroceptive stimuli, as discussed above, or to the responsiveness of the corpus luteum to prolactin. Recently, Johke (1970) and Koprowski \& Tucker (1973) suggested the possibility that in the cow the hypothalamic sensitivity to milking might be altered as lactation advanced. It is very interesting to recall the findings of Ôta et al., (1974) demonstrating a loss of corticosterone release in response to suckling in prolonged lactation. Studies, however, involving the serial blood collection throughout the normal and prolonged lactation are required to draw a final conclusion. 


\section{Acknowledgements}

We are most grateful to Dr. A. T. Cowie, National Institute for Research in Dairying, England, for reading the manuscript. Our thanks are also due to Mr. R. Ogawa and Mrs. Y. Niwa for their assistance.

\section{References}

Amenomori, Y., C. L. Chen and J. Meites (1970). Endocrinology, 86, 506.

Bruce, H. M. (1961). J. Reprod. Fertil., 2, 17.

Ford, J. J. and R. M. Melampy (1973). Endocrinology, 93, 540.

Grosvenor, C. E., H. Maiweg and F. Mena (1970). Horm. Behav., 1, 111.

Hammons, J., M. Velasco and I. Rothchild (1973). Endocrinology, 92, 206.

Johke, T. (1970). Endocrinol. Japon., 17, 393.

Kurz, M. (1967). Symposium on Reproduction Congr. Endocrinol. and Metabolism. p. 175.
Koprowski, J. A. and H. A. Tucker (1973). Endocrinology, 92, 1480.

McCann, S. M. and V. D. Ramirez (1964). Rec. Prog. Horm. Res., XX, 131.

Mena, F. and C. E. Grosvenor (1972). J. Endocr., $52,11$.

Nicoll, C. S. and J. Meites (1959). Proc. Soc. exp. Biol. Med., 101, 81.

Ôta, K., Y. Harai, H. Unno, S. Sakauchi, H. Tomogane and A. Yokoyama (1974). J. Endocr., 62, 679.

Rothchild, I. (1960). Endocrinology, 67, 9.

Selye, H. and T. McKeown (1934). Surg. Gynec. Obst., 59, 886.

Terkel, J., C. A. Blake and C. H. Sawyer (1972). Endocrinology, 91, 49.

Thatcher, W. W. and H. A. Tucker (1968). Proc. Soc. exp. Biol. Med., 128, 46.

Tomogane, H., K. Ôta and A. Yokoyama (1969). J. Endocr., 44, 101.

Tomogane, H., K. Ôta and A. Yokoyama (1975). J. Endocr., 65, 155.

Tomogane, H., K. Ôta and A. Yokoyama (1976). $J$. Reprod. Fertil. in press.

Yanai, R. and H. Nagasawa (1973). Hormone Res., 4, 169. 